\title{
SharePoint Foundation 2010 Picture Library as a Searchable Photo Database in a Small Library: A Program Description ${ }^{1}$
}

\author{
Tanya Young Harron
}

\begin{abstract}
In the digital age, librarians are being consulted on unique projects that are outside of the traditional role of responding to information requests. This paper examines the role of a solo health librarian who was tasked with locating and creating a digital photo database for her organization's small collection of digital photographs, clipart, and logos. The selection of SharePoint Foundation 2010 picture library as the organization's photo repository is discussed, as well as the steps taken by the librarian to create the database, issues with cataloguing the collection, and pros and cons of the software.
\end{abstract}

\section{Introduction}

Implementing a database for digital images can be overwhelming. As well as the expense of new software, some may find they lack the technical knowledge required to ask the right questions when making a decision regarding which product to purchase or use. Privacy and copyright concerns can also come into play when pictures are of individuals, were taken by others, or involve licensing agreements.

Although a number of articles in the literature discuss the software used in digital photo collections, these tend to be for archival or academic institutions that offer public access to a large collection. The collection discussed in this paper belongs to a small health unit serving approximately 200 staff. It is composed of hundreds of photos that were licensed from a professional photographer or organization, taken by staff, or purchased from an outside source for use in a specific poster or brochure.

\section{Description}

In 2011, prior to the creation of a photo database, the organization's collection of several hundred digital photos, logos, and clipart were arranged in windows folders on a shared hard drive accessible only to a small number of staff. These photos were JPEG (joint photographic experts group), TIFF (tagged image file format), BMP (bitmap image file), or GIF (graphic interchange format) files. The photos were arranged by the year in which they were taken, created, or purchased and were titled in a hap-hazard fashion depending on who had titled or downloaded the photo. As a result, specific photos were hard to locate or difficult to match with a signed photo consent or licensing agreement. This became an issue for staff in terms of time spent looking for appropriate photos and money spent repurchasing the same or similar images. As the "catalogue expert" the organization's librarian was assigned the task of locating a searchable database for the images and creating the organization's "photo library".

As a first step, the librarian consulted with other librarians in similar environments (public health librarians, hospital librarians, and consumer health librarians) to see if they were using any software to organize their digital photos. Of the librarians consulted, none were responsible for cataloguing or organizing digital photos in their organization or could offer any recommendations on software. Next, a literature search was conducted on Library, Information Science \& Technology Abstracts database using the terms "photograph collection*" OR "photo collection*" OR "picture librar*" AND "digital collection.*" In conducting this search the librarian wanted an answer to the question: "What is the software solution to organizing a digital photograph collection in a small library?" Furthermore, the librarian was hoping that once software was selected, there would be articles or howto guides on design and (or) implementation. Many articles were found on preserving and cataloguing large digital collections with fee-based solutions and (or) open source software [1-3]; however, these solutions were discarded based on the limited budget for this project and the available support from the IT department. Other articles

Tanya Young Harron². Librarian, Wellington-Dufferin-Guelph Public Health, Guelph, ON. Phone: 519-822-2715 ext 4375. Fax: 519-

836-7215

${ }^{1}$ This article has been peer reviewed.

${ }^{2}$ Corresponding author (email: tanya.harron@wdgpublichealth.ca; tanya_harron@sympatico.ca). 
on digital image collections suggested using social media platforms such as Instagram or Flickr [4-6], these were not considered due to security concerns and the private nature of the collection.

In consultation with the organization's information technology staff, it was suggested that as InMagic DBTextWorks was the platform used for the library's collection of books and DVDs, it would be a good fit for the photo library. That idea was discarded as the agency only had one license for this product and there would be several people responsible for uploading and retrieving photos. As well, the database could not be used from computers outside of the office location due to the agency firewall. This would be a hindrance to any staff working from home.

The organization had been using Microsoft SharePoint Foundation 2010 [7] since 2009 as a document management system to manage and organize electronic files relating to specific projects. According to Microsoft, SharePoint "is the essential solution for organizations that need a secure, manageable, web-based collaboration platform" [7]. Many staff were comfortable searching the interface and several staff, including the librarian, had experience with posting and editing documents. On investigating SharePoint as a possible solution, the librarian discovered the option of the "picture library" function within the software.

SharePoint picture library was selected for several reasons:

- For the organization there was no extra cost to using SharePoint. Creating the picture library was not a time-consuming, expensive project.

- The SharePoint platform allows for user name and password access so that access to the site could be restricted to staff only.

- It allows one or more people to be given editing rights to the pictures and photos and also allows for a group of users to be given read only rights. This was essential for two reasons. Only a handful of people would be uploading photos to the site. Also some photos had specific licensing restrictions that only allowed for specific use, so downloading had to be monitored in some way.

- Photos can be tagged with keywords, which allows for searching via the SharePoint search feature.

- Knowledge of computer programming language was not required to create the database.

- SharePoint is accessible from anywhere as long as there is an Internet connection and a browser.

The information technology staff created the picture library site, along with the appropriate permissions and administrative privileges. The librarian was responsible for designing the site and uploading the photos. Prior to uploading the photos to the SharePoint site, the librarian arranged the photos into subject-specific folders and created a controlled vocabulary for tagging the photos. The site was than designed with a home page that included instructions on using the library, a copyright warning, and a link to the search page. The search page included the subject-specific folders so that staff had the option to browse rather than search the site via keyword. Photos were uploaded quickly using SharePoint's batch upload feature. The photo library was than promoted to staff via the employee electronic newsletter.

\section{Outcomes}

A year after the site was created; an informal survey of 22 staff that had used or possibly used the picture library was conducted by the librarian. To put this number into context, in a typical month, the number of unique visitors to the picture library per day was anywhere from zero to six individuals. The staff surveyed included 13 health promotion specialists, four program assistants, and five dietitians. Participants were selected based on one of two things, their names being listed as a top visitor in the photo library's web analytics report (a feature of SharePoint) or a referral to the picture library by another staff person. The survey was conducted via email and a reminder email was sent to those who had not responded after one week.

Of those surveyed, nine completed the survey $(41 \%)$ and one individual responded that they had not used the picture library, so they could not complete the survey. Results were analyzed using cross tabulation, showing the results of the survey questions by subgroup. Of the 10 respondents, two were dietitians, three were program assistants, and five were health promotion specialists. All respondents $(100 \%)$ that had used the picture library said that it was easy to use, and they would use it again. Suggestions for improvement included: adding more pictures, adding more keyword tags, providing reminders of picture library's existence, and providing an indication of picture's last use (see Appendix A for survey results).

Based on feedback provided by this survey, some changes were made to the picture library. Two additional fields were added to the picture library records. A "notes" field was added so that information regarding whether a picture was used in a specific campaign could be included and a "copyright information" field was also provided. The copyright field was added as the survey led to a dialogue that people were downloading pictures through their browser's "save target as" option rather than ordering the picture through the administrators of the site, as was originally intended. Communicating to staff that administrators could provide better quality pictures to end users and rewriting the copyright warning in a red font on the home page of the site was the resolution to this issue.

\section{Discussion}

Although the keyword tagging option works very well in SharePoint Foundation 2010, it is not intuitive enough to pick up on different spellings or inclusion of part of a term. For example, if a photo is tagged with the word "bedbugs" and the term "bed bugs" or "bugs" is typed in the search interface the photo will not be found. Boolean operators or wildcard characters such as the asterisk $(*)$ are also not recognized. However, you can include or exclude keywords by using the plus $(+)$ or minus $(-)$ sign in front of the keyword. From a cataloguing point of view, the software does not allow a listing of keywords already used to be seen by the cataloguer. The solution has been to tag photos with 
as many keywords and derivatives as possible. Because there are several people uploading and tagging photos, this has been and continues to be a challenge, and the controlled vocabulary that was created for tagging the photos has been abandoned. It is important to note that other versions of Sharepoint such as Sharepoint Server edition 2010 and 2013 do not share the same limitations with regards to formal taxonomies and the inclusion of synonyms for alternate spellings of a term. Both include a term store management tool, a managed metadata column, and an enterprise keyword column [8].

The database seems to work best in the Firefox and Internet Explorer browser. As an example, staff noticed that when viewing the photo collection through Google Chrome the scroll option wasn't available. Ennis and Tims [9] say it best; "SharePoint is a Microsoft product, so it works better in Internet Explorer (IE). It works in other browsers but there may be more clicks and less fluidity".

The copyright issues of staff having access to photos with copyright restrictions is concerning but anyone using the Internet can right click an image on a website and download it to their computer so this may be an issue which has no remedy, although the librarian is still investigating whether there is any way to prohibit users from downloading photos from the site. Continuous copyright education, reminders, and fostering a culture of respect for the intellectual property rights of others are the interim solutions.

Deciding on a digital photo management tool for our small library collection was challenging, due to the limited amount of library literature for a small collection and the lack of expertise from other librarians in similar environments. Once the decision was made to investigate SharePoint as an image repository it became clear that there was also an absence of literature regarding its use in the library setting, although many articles were found on using SharePoint in libraries as document repositories, collaborative tools, and extranets [10-12]. In a survey of how librarians use SharePoint in 2010, it was noted that the pictures library tool was used only by libraries in the government sector [11].

Despite its limitations, the picture library has been successful with both end users and contributors at this organization not only for its ease of use but also for the limited amount of training needed to use the software for both searchers and uploaders due to its familiar Microsoft interface. Photos are no longer missing or difficult to locate and staff are spending less time searching for appropriate photos for various projects.

Although only $10 \%$ of staff was surveyed in this organization, the survey results are a good representation of how SharePoint picture library is perceived by users as that is the approximate percentage of staff currently using this tool. Future directions may include marketing to other staff not currently using the picture library as well as a survey of database uploaders.
A small library with a relatively small collection of digital images may find the picture library to be the solution to their digital collection requirements, assuming they already have access to SharePoint, have a minimal budget, and limited staff time. This is especially true if the needs of the organization are basic and only include organizing and tagging a small collection of photos for use by specific individuals.

\section{References}

1. Dunlop IH. Open source: digital image management. Comput Libr. 2005;25(4):6-48.

2. Introducing D-Space. Rec Manag Soc Bull. 2004;121:38.

3. Cromptom P. The development of a digital image database of clinical photographs. J Audiov Media Med. 2000;23(2):54-60.

4. Free D. NCSU Libraries shares open-source solution for crowdsourcing photography collections. C\&RL News. 2013; 74(9):464-465.

5. Kalfatovic M, Kapsalis E, Spiess K, Camp A, Edson M. Smithsonian team flickr: a library, archives, and museums collaboration in web 2.0 space. Archival Science. 2008; 8(4):267-277. doi: 10.1007/s10502-009-9089-y.

6. Ang S, Pwee T. Working with the public: flickr SNAP (Singapore National Album of Pictures). Microform \& Imaging Rev. 2009;38(1):30-33.

7. Microsoft Corporation. [Microsoft Download Center] Microsoft SharePoint Foundation 2010. 10 May 2010. [Internet]. Available from: http://www.microsoft.com/en-ca/download/ details.aspx?id $=24983$

8. Microsoft Corporation. [Office Online] Introduction to managed metadata. [Internet]. Available from: https://support. office.com/en-us/article/Introduction-to-managed-metadataa180fa28-6405-4679-9ec3-81d2028c4efc?ui =en-US\&rs =en$\mathrm{US} \& \mathrm{ad}=\mathrm{US}$

9. Ennis LA, Tims RS. Harnessing the power of SharePoint for library applications. Comput Libr. [Internet]. 2010;30(5). Available from: http://www.infotoday.com/cilmag/jun10/Ennis_ Tims.shtml

10. Monte C. SharePoint: a librarian's most versatile tool. $A A L L$ and ILTA digital white paper: the New Librarian. [Internet]. Available from: http://www.aallnet.org/main-menu/Publications/ products/aall-ilta-white-paper/sharepoint-2.pdf

11. Weldon LSJ. SharePoint is plug and play for librarians. [Internet]. Available from: http://www.governmentinfopro. com/files/sharepointplug_play_librarians_weldonfinal.pdf

12. Weldon LSJ. Sharepoint without coding: my notes for embedding the Librarian. College Park, MD: Lorette SJ Weldon MLS; 2010.

\section{Appendix A}

Appendix A appears on the following page. 


\section{Appendix A: SharePoint picture library survey results}

\begin{tabular}{lccl}
\hline Respondent & Is it easy to use? & Would you use again? & Suggestions for improvement \\
\hline PA & Yes & Yes & More inspection pictures. \\
HPS & Yes & Yes & No \\
HPS & Yes & Yes & More tags for pics. \\
PA & Yes & Yes & No \\
HPS & Yes & Yes & No \\
HPS & Yes & Yes & Remind people it exists. Trouble with sizing pics that have \\
& & & Would like to see an indication of where photo was used \\
HPS & Yes & Yes & before such as campaign, report, etc. \\
& & & More pictures \\
PA & Yes & Yes & More keywords for pics. \\
Dietitian & Yes & Yes &
\end{tabular}

Note: PA, program assistants; HPS, health promotion specialists. 